\title{
THE FOUR-MASTED BARQUE PEKING IN VIRTUAL REALITY AS A NEW FORM OF KNOWLEDGE TRANSFER
}

\author{
T. P. Kersten ${ }^{1, *}$, D. Trau ${ }^{1,2}$, F. Tschirschwitz ${ }^{3}$ \\ ${ }^{1}$ HafenCity University Hamburg, Photogrammetry \& Laser Scanning Lab, Überseeallee 16, D-20457 Hamburg, Germany \\ (Thomas.Kersten, Dominik.Trau)@hcu-hamburg.de \\ ${ }^{2}$ Agency for Geoinformation and Surveying, Neuenfelder Straße 19, D-21109 Hamburg, Germany Dominik.Trau@gv.hamburg.de \\ ${ }^{3}$ IB\&T Software GmbH, An'n Slagboom 51, D-22848 Norderstedt, Germany - Felix.Tschirschwitz@card-1.com
}

Commission IV, WG IV/9

KEY WORDS: 3D, Animation, Games Engine, Interaction, Modelling, Reconstruction, Visualisation

\begin{abstract}
:
Virtual Reality (VR) has established itself in recent years in the geosciences through its application in the immersive visualization of spatial data. In particular, VR offers new possibilities for the user to acquire knowledge through playful interaction within a virtual environment. This paper details the development and implementation of a new form of knowledge transfer, based on interactivity within a VR system. The particular use-case discussed is a VR application focusing on the four-masted barque Peking. From 2023 on, the restored ship will form an important exhibit in the future German Hafenmuseum in Hamburg. The new VR application offers users the possibility to enter and explore a virtual model of the Peking and find out more information at three separate points of interaction (3D object models, sails and ship flags). These interaction points provide a timely opportunity to examine several of the theoretical aspects of knowledge transfer through interactivity and integrate them in the development of the VR application. Above all, the VR application should be an important part of the learning process for the user. There remains still much potential for further research into more advanced approaches such as support for user-input questions and tailored content.
\end{abstract}

\section{INTRODUCTION}

In the early days of VR, there were limited applications outside of larger research laboratories and military facilities (Dörner 2013). However, thanks to the advent of low-cost virtual reality systems in the mid-2010s (Oculus Rift, HTC Vive) and improved availability and licensing possibilities of game engines, this technology is now available to a wider public and is expected to make an important contribution to the future media landscape.

More and more VR experiences deal with areas or objects that are no longer in existence, such as historical cities or cultural sites (Deggim et al. 2017; Tschirschwitz et al. 2019; Walmsley, Kersten 2019). The full potential of these generated virtual environments using specific game engines offers more than static visualisation and presentation of cultural assets to the user. The integration of interactive elements can be used to promote education through entertainment (known commonly by the portmanteau "edutainment"), in particular for younger audiences and user groups that are not so well-versed in the subject. Furthermore, the implementation of dynamic elements offers an enhancement of the immersive experience for the viewer.

Using the example of the four-masted barque Peking, various points of interaction allowing additional information to be conveyed have been developed and tested within the virtual environment. What results is a new form of knowledge transfer that includes both historical information pertaining to the ship, as well as information about the development process of the VR application. This latter subject is important to present as the VR experience is targeted at the general public and not only at selected experts.

\footnotetext{
* Corresponding author
}

The goal of this project was to virtually re-construct a historical ship in detail in $3 \mathrm{D}$ in order to develop a VR application including interactions to demonstrate the potential of virtual reality for knowledge transfer in museums.

\section{METHODS}

For the development of the interactive VR application and visualization of the four-masted barque Peking, the game engine Unreal Engine 4.22.3 from the software company Epic Games Inc. was used. For the hardware, the Vive Pro head-mounted display from HTC and Valve Corporation was chosen.

For the upcoming permanent exhibition in the future German Hafenmuseum, the four-masted barque Peking (Figure 1 left) was virtually restored to its $1927 / 1928$ state. To create the virtual ship Peking (Figure 1 right), 3D models and plans were acquired from sources in the shipping industry, and information on the ship and the ship's inventory recorded by geodetic methods (photogrammetry and terrestrial laser scanning (TLS)).

The Peking is a four-masted steel barque, commissioned by the F. Laeisz shipping company and built from 1910 to 1911 by the Blohm + Voss shipyard in Hamburg. The ship is over $115 \mathrm{~m}$ long and has four masts of up to $50 \mathrm{~m}$ in height. Its long and varied history has been described in detail by the association "Freunde der Viermastbark PEKING e.V." (2020) ("Friends of the fourmasted Barque Peking"). Until shortly after the years 1927/1928, the ship was used to transport saltpetre from Chile to Europe and then, after some conversions, served as a training ship for naval officer candidates. In 2017 the Peking returned from New York to Germany after several changes of ownership. The historic ship is currently undergoing restoration at the Peters shipyard in the 


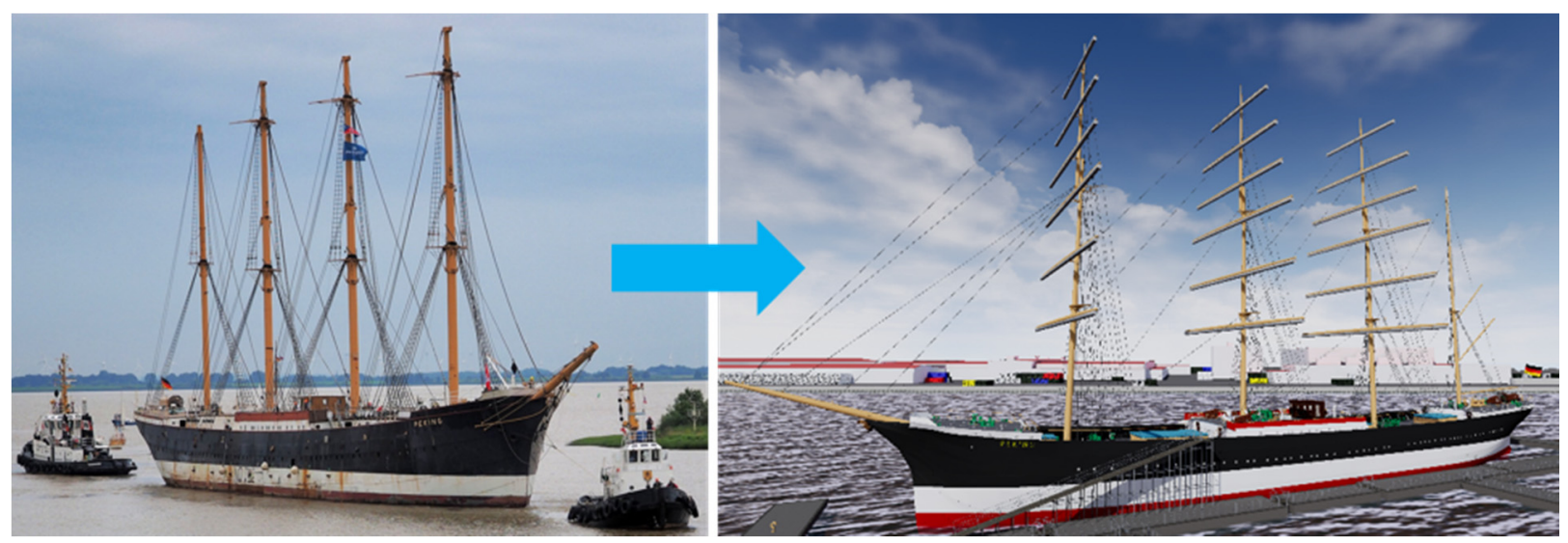

Figure 1. The Peking in the year 2017 after its transfer from New York to the Peters shipyard in Wewelsfleth at the entrance of the river Stör (left, photo: Stiftung Hamburg Maritim) and the virtual reconstruction of the ship (right)

village Wewelsfleth $(60 \mathrm{~km}$ northwest of Hamburg near Glückstadt), and will likely be one of the flagships of the future German Hafenmuseum in Hamburg from 2023.

In the following, special emphasis is given to those parts of the visualisation process that differ significantly from previous approaches in VR visualization. First, the entire workflow is presented, with special attention given to the data formats used, before the implementation of dynamic and interactive elements is described in more detail.

\subsection{Development of the VR application}

The Hansa Harbour in Hamburg's Kleiner Grasbrook quarter was chosen as the "virtual berth" of the Peking, as it offers a visually closed-off area and was indeed the ship's historical anchorage during its active period. Surrounding environmental objects such as buildings, quay walls and vegetation were only rudimentarily generated so as not to reduce distraction from the main object of investigation, the ship itself. An overly detailed design risks focusing the viewer's attention on these environmental elements at the expense of the ship. The LoD2 (Level of Detail) models from the Hamburg 3D city dataset were used for the placement of building meshes lining the harbour, limiting the user's view from the ship deck and contributing to the overall immersive effect of the environment. These data as well as the digital terrain model (grid width $=1$ meter) used for the landscape topography are freely available from the Agency for Geoinformation and Surveying Hamburg.

Figure 2 illustrates the area of the Hansa Port, which was reconstructed as an environmental backdrop to the experience and which is divided in three thematic themes. It is explicitly not the aim of this reconstruction to depict the real environment, but rather to give an impression of the typical port characteristics that exist in this area.

In the northern area, containers, loading cranes and walls were added to the scene in addition to the existing logistics complexes. The second thematic area in the south encloses the headquarter buildings of the Hamburg Port Authority (HPA) and is, in its current state, mainly hidden behind trees and bushes. Meanwhile,

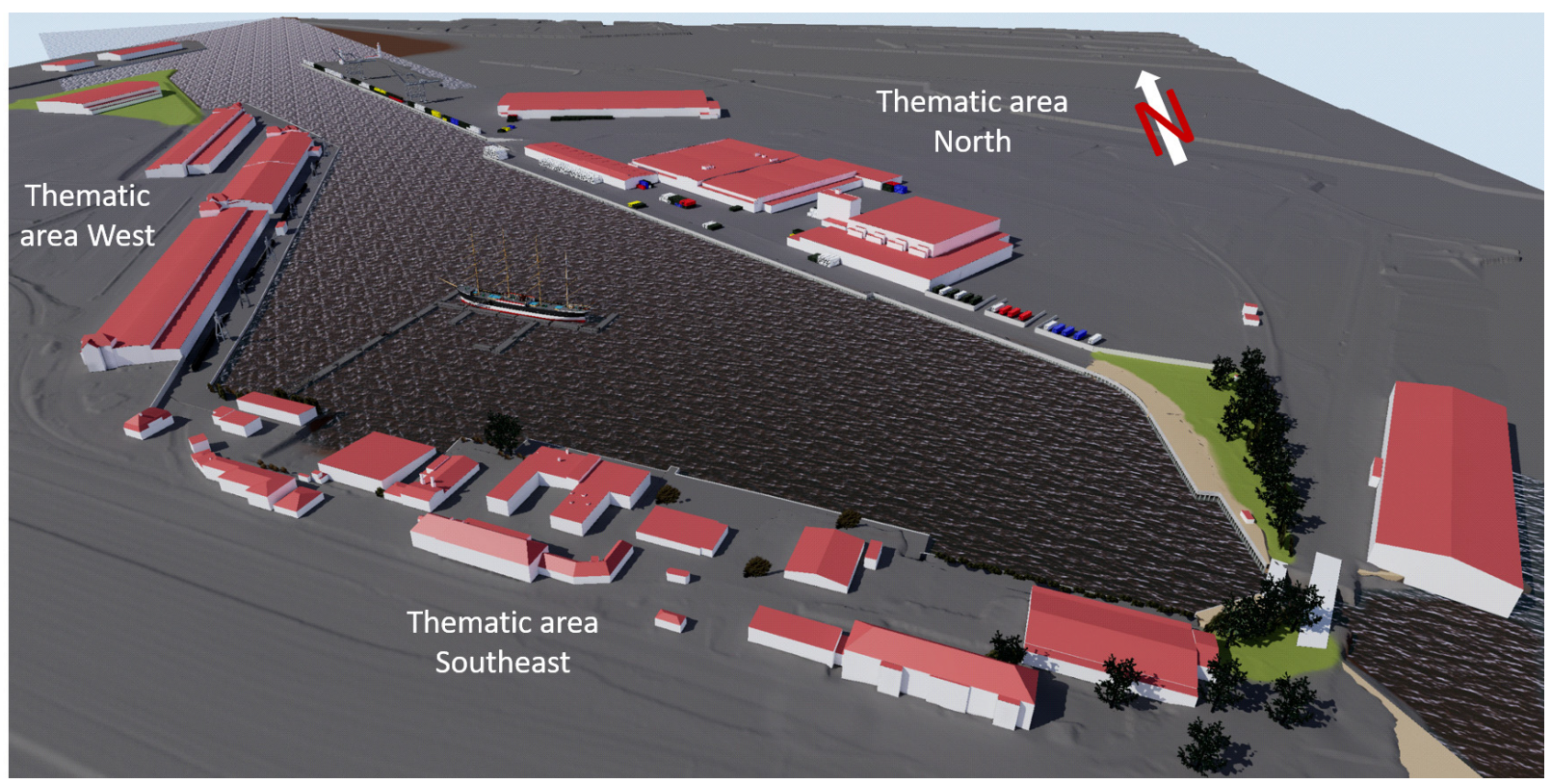

Figure 2. The virtual berth of the Peking in the VR application: Hamburg's Hansa harbour with surrounding buildings acting as visual barriers 
the third thematic area is located at the western end of the port basin and encloses the historic sheds no. 50 and 51, which served as a cargo handling area at the beginning of the 20th century. Today there are still many cranes and wagons present, which were integrated into the VR application as scenery props.

One of the central objectives of the project was to create a detailed 3D model of the Peking to be visited and experienced virtually from a First Person View (FPV). To this end, digital 3D models from companies involved in the restoration of the ship were used for the creation of the hull. To overcome the differing states of development and complexity of these 3D models, other sources such as a dense point cloud of the hull from terrestrial laser scanning, as well as the original construction plan from 1910, were also exploited. From all these data sources, the most extensive and detailed areas were selected and the ship virtually constructed over several development stages.

For the modelling of the deck superstructure (e.g. Figure 3 bottom), details were carried over from the Peking's identical sister ship, the Passat (Figure 3 top), anchored in Travemünde (the port of the Hanseatic city of Lübeck) as a museum ship. In addition, the original ship construction regulations of the Peking provided important information. The general process of CAD modelling on the basis of various data has already been dealt with in detail in the literature and in other projects. Two examples of a detailed 3D modelling workflow can be found in Kersten, Lindstaedt (2012a) or Kersten et al (2014).

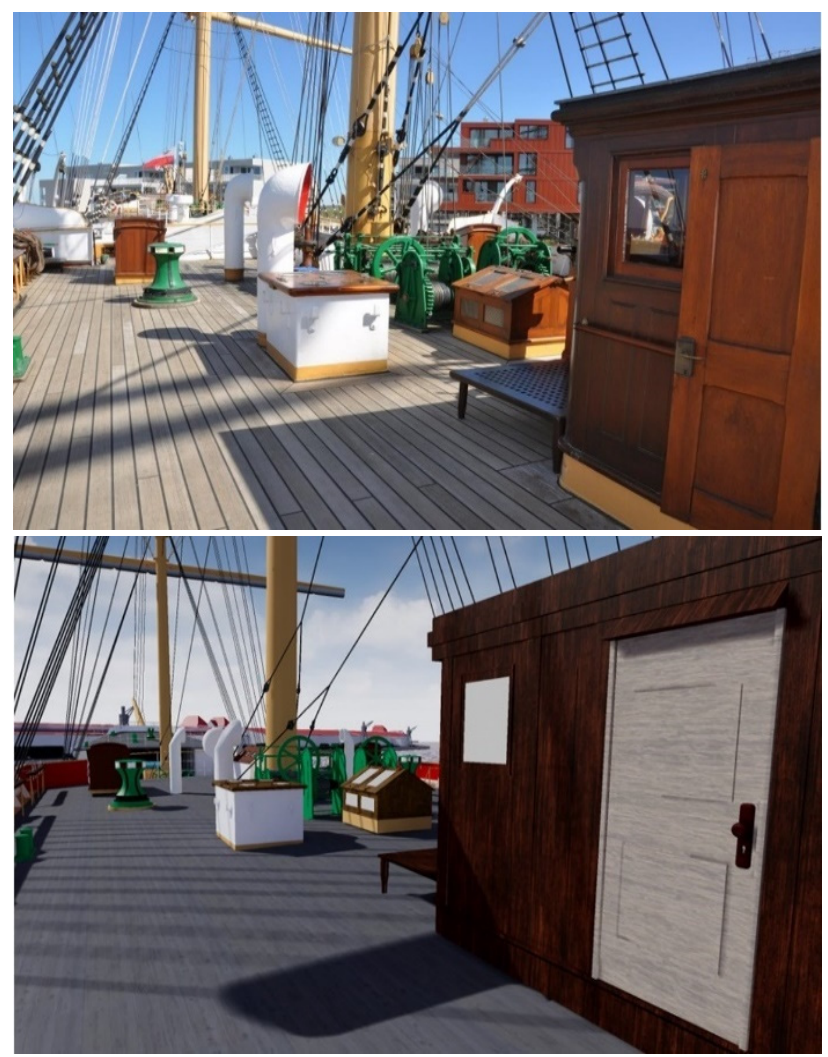

Figure 3: View over the main deck of the sister ship Passat (top) and over the virtual main deck of the Peking (bottom)

The Peking was not accessible for this project's duration as it is in the shipyard for restoration (see Ulrich 2020a). The only two elements of the ship available in Hamburg (the auxiliary steering wheel in the Museum of Hamburg History and the figurehead in the International Maritime Museum Hamburg) were recorded using photogrammetry and integrated within the virtual ship as interaction points. A total of 544 working hours were spent on the visualisation of the ship and its surroundings including the development of interactive elements. A large part of this work (238 hours) was spent on CAD modelling; a figure similar to other modelling projects (e.g. the "Old-Segeberg Town House" in Kersten et al. (2014) and the "Imperial Cathedral Königslutter" in Kersten, Lindstaedt (2012b)). The time spent developing the VR application (222 hours) is correspondingly extensive, since individual concepts first had to be developed. For similar projects in the future the numbers of hours necessary can be assumed to be lower due to the experience gained on this project.

Multiple visualisation modes are presented to the viewer by means of interactive elements within the VR application. In this project two objects were selected as examples, which are presented as point cloud, triangular meshing, CAD model and photography. For this purpose the original figurehead and the auxiliary steering wheel of the Peking were photogrammetrically captured with a Nikon D800 and processed accordingly to generate the corresponding data formats. In the course of the photogrammetric evaluation an accuracy of $0.2 \mathrm{~mm}$ (figurehead) and $1.8 \mathrm{~mm}$ (steering wheel) was achieved for scaling the point clouds, though this high level of precision has no significant influence on the modelling of the ship.

To improve the run-time efficiency of the VR application, it was decided not to animate the sails permanently for simulating wind conditions, but instead start the experience with them furled at the booms only at user's request. Through a simple interaction within the virtual world (see also chapter 2.3.), a matinee (Epic Games 2020), an animation sequence, can be triggered, activating the hoisting of selected sails. Within five seconds, selected groups of sails are iteratively scaled until the sails are fully set, simulating uninterrupted movement (Figure 4). By activating and interactively hoisting the sails, the user is encouraged to get information and/or to learn knowledge about the sails independently, including their position and designation (see chapter 2.3.).

\subsection{Dynamic components of the VR application}

It is also possible in VR to simulate natural movements of objects due to environmental stimuli such as to make the scenery appear more alive. Conventional applications that reproduce reality as a visualised 3D model may have scientific accuracy, but immersion for users is limited through a lack of other sensory stimuli. In this VR experience, the waves and swell of the water in the harbour is simulated by applying a predetermined animated offset, such that certain points on the water's surface move vertically in space over time. The effect is heightened by the use of special lightmaps that provide to the game engine information on the normal direction and specularity of the water's surface, depending on the angle of view of the observer.

Furthermore, the effect of sails flapping in the wind is simulated using the Verlet algorithm (Jakobsen 2001). For this purpose, planes were generated and then subdivided to produce thousands of faces. Each of these faces was classified into a number of vertex groups, some of which were designated as static while others as mobile, and thus could deviate from the assigned position under the influence of external forces such as wind and gravity. These conditions were created in the game engine, thus allowing the sails to be affected correspondingly. 

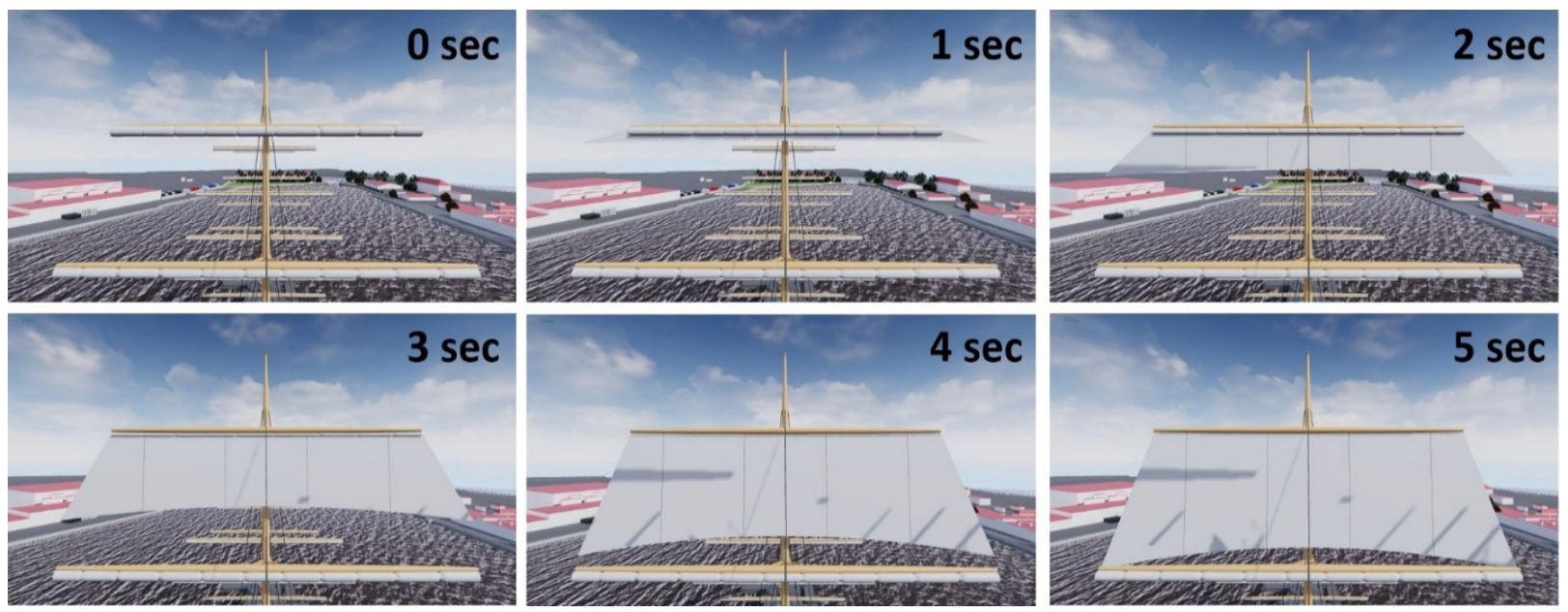

Figure 4. Hoisting of the pre-royal sail as a matinee sequence

\subsection{Implementation of interactive elements}

In addition to the visualisation, interaction points were integrated to boost the immersive effect of the environment. These interactions, as well as the resulting processes, have been designed with regards to different forms of knowledge transfer as well as to the requirements of interactivity in order to investigate the suitability of VR systems for this purpose.

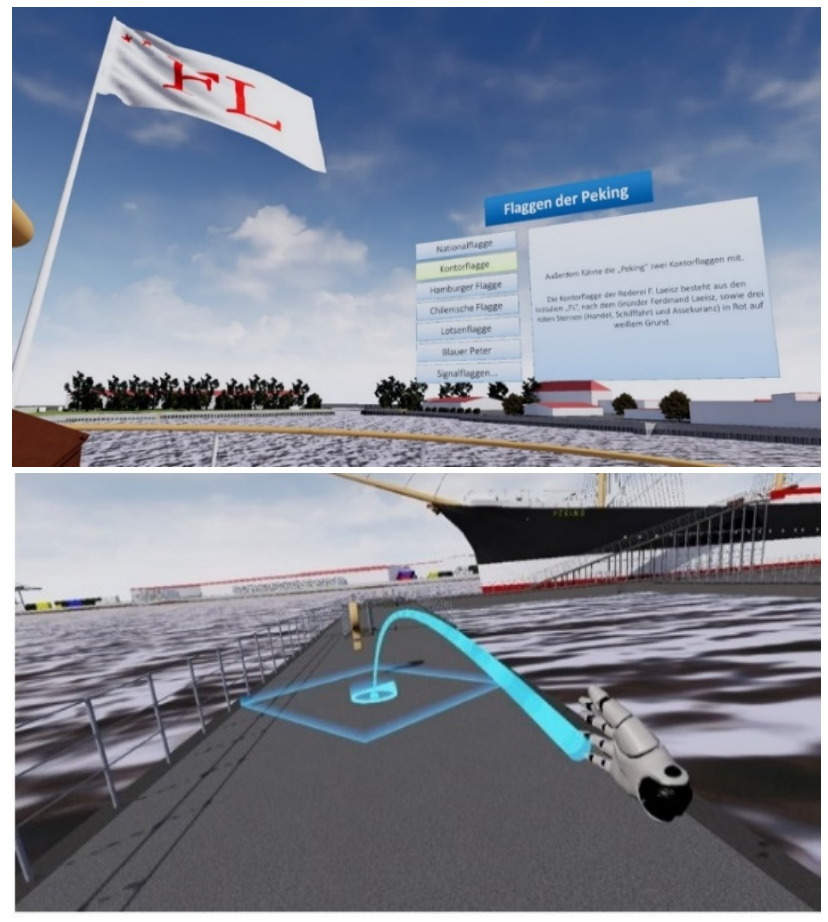

Figure 5. The interactive menu "Flags of the Peking" (top) and targeted locomotion through teleportation in the VR model

(bottom)

In the following, all three interactive menus developed for the application are described and explained. Within the VR world, the user is able to teleport from one location to another by means of a hand controller (Figure 5 bottom). Upon entering certain marked areas (indicated by rotating questions marks, see Figure 9 at the afterdeck), interactive menus appear allowing viewers to access additional information by selecting from different options and through this gain new knowledge about the ship. The interaction always results in a change in the environment and the display of additional information in the form of images, 3D models and animations. This process represents a considerable advantage over the gathering of information in reality, since on a real sailing ship such effects or animations are not possible at the push of a button.

Figure 5 (top) shows the first interactive menu. Through this interaction, the user can view each of the flags of the Peking and obtain more information about each. The structure of the menu is very similar to the two examples that follow, minus a short introductory text. By pressing one of the buttons, the corresponding flag is hoisted on the flagpole at the stern of the ship and an explanatory text appears on the right-hand side of the interface (Figure 5 top).

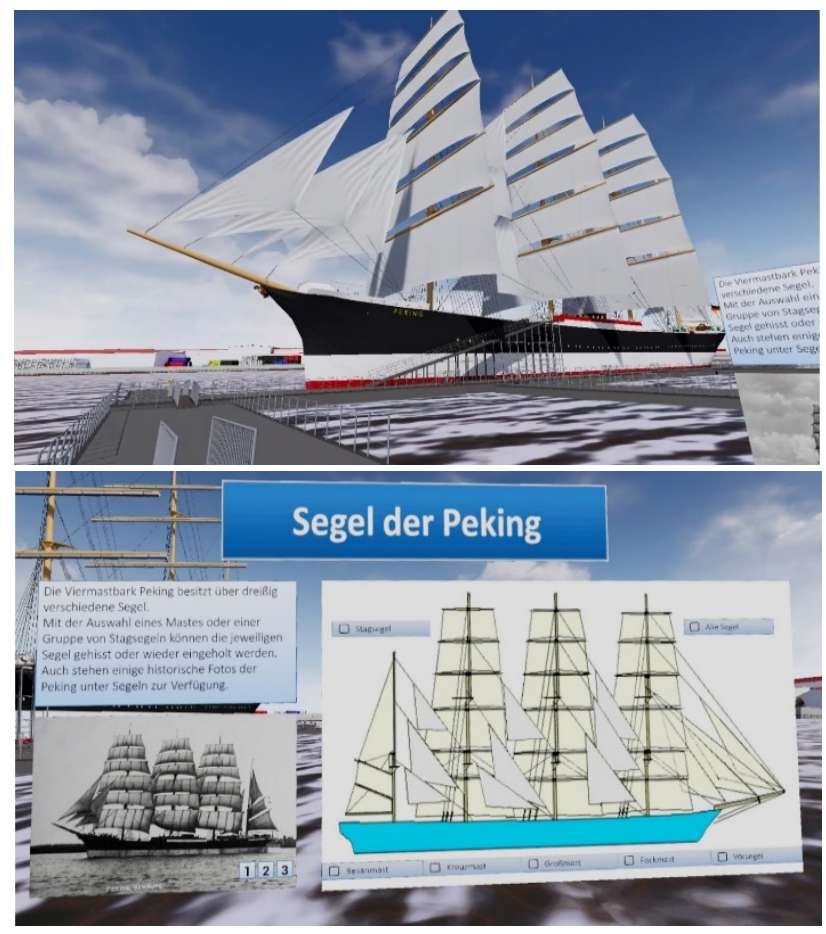

Figure 6. The interactive menu "Flags of the Peking" (top) and targeted locomotion through teleportation in the VR model (bottom) 
A second interactive menu allows users to access information about the sails of the Peking (Figure 6). Like the other menus, the layout is divided into three sections. The section heading is located at the top of the interface. Below this there is always an introductory paragraph. Most of the screen space of the interface is dedicated to the interactive element itself. Besides being able to view a series of historical images in the bottom left-hand corner, the user is able to select one, several or all checkboxes of the graphic on the right-hand side of the interface (Figure 6 bottom). Depending on which checkboxes are ticked, the sails of the respective mast are then highlighted on the diagram, so that the name and position of the sails can be learned. At the same time, the hoisting animation plays on the $3 \mathrm{D}$ model in the virtual world, as described in chapter 2.1 (Figure 6 top). This process can also be reversed by clicking again on the selected checkbox.

The third menu offers the possibility to display objects of the ship (figurehead and auxiliary steering wheel) using different visualisation methods. The interaction is designed in such a way that the user can activate different options when in the immediate vicinity of the figurehead at the front of the ship (Figure 7 bottom) or the auxiliary wheel on the midship deck (Figure 7 top). The structure of the interface is similar to the other interactive menus. With the help of several checkboxes, the viewer can select a preferred visualisation form, whereupon the object appears accordingly in front of the user. For the point cloud and meshing format, it is also possible to show different levels of detail. In addition, an explanatory panel appears to the left of the object, divided into textual and visual parts and explaining the creation process for the respective data formats over several pages. This provides the user with explanations of how photogrammetry and CAD modelling can be used to generate such virtual objects.

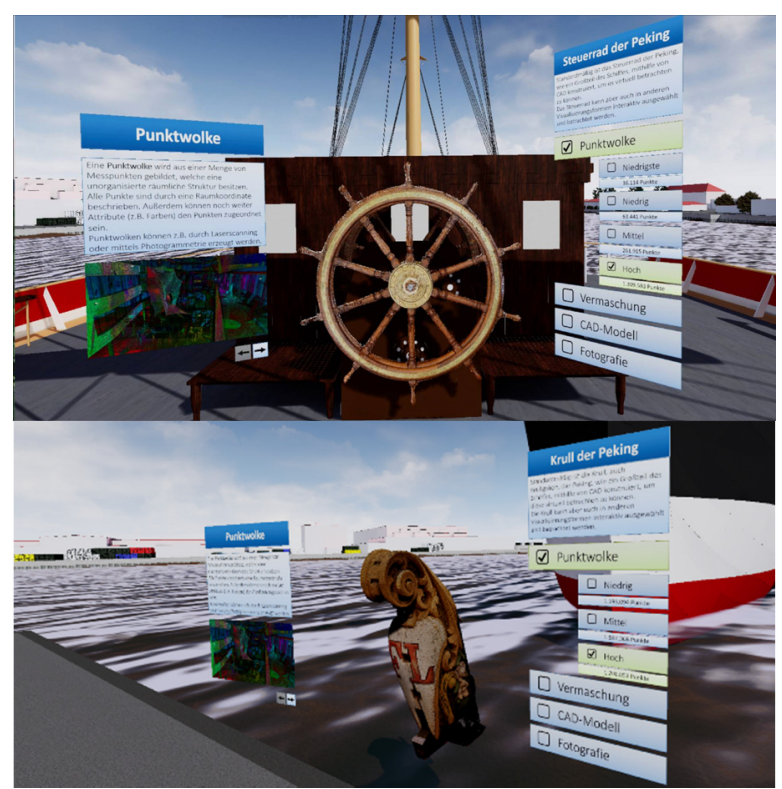

Figure 7. Interactive menus "Peking wheel" (top) and "Peking figurehead" (bottom)

\section{RESULT}

Following the development of the VR application for the Peking, a differentiated analysis of the results took place. For this purpose different criteria have been taken into consideration. Qualitative features, such as the interactive elements, are examined more closely before the required computing power is reflected from a quantitative point of view.

\subsection{Interactive knowledge transfer in the case of the Peking}

This chapter is divided into two parts, with the focus on knowledge transfer. First, some central theories of knowledge transfer are listed and examined with regard to the VR application created. In the second part a stepwise scale of interactivity is introduced, which is compared to the interactive elements implemented in this VR experience.

In the following, central theories of knowledge transfer (Benkert 2001; Issing, Klisma 2002; Dörner 2013) are listed together with a short explanation and a short consideration as to what extent they could be implemented in the VR application:

- Situatedness and authenticity - These factors play an important role in the success of the learning process. Knowledge transfer is facilitated if, on the one hand, the learning content is put into context with respect to existing knowledge and, on the other hand, if learning takes place in a specific or authentic environment.

- In the VR application, the four-masted barque offers an authentic environment and knowledge acquisition takes place using familiar structures. All interaction menus have a consistent scheme (similar keys always generate additional information and cause a change in the virtual world), supporting the user in learning the principle of action.

- Multiple contexts - Another factor that facilitates learning is the occasional change of perspective and variation of situations and tasks.

- Due to the proper motion in the virtual environment, the user can vary his perspective at will.

- Social context - In addition, the transfer of knowledge is favourably influenced when there is an exchange with other people, regardless of their expertise.

- Social interaction with other people is currently only possible to a limited extent.

- Self-control and cooperation - Furthermore, the learner is motivated to acquire more information if he or she has free choice of learning method. Cooperation with additional persons also helps to open up new perspectives.

- With the developed VR application, the viewer is free to choose their own learning strategy.

Another issue is interactivity, for which there is no uniform classification due to the many disciplines involved. Issing and Klisma (2002) establish the following scale, which represents the gradual increase of interactivity and is compared section by section with the VR application described above.

- Access to specific information

- In the VR application several interaction possibilities are implemented allowing further information to be displayed.

- Yes/no and multiple choice answer options

- All interactive menus allow the selection of individual options, as well as allowing for the combined selection of several checkboxes.

- Activation of certain additional information

- The interactive components are designed to provide additional explanations and information.

- Complex questions with intelligent feedback

- The user in this VR application can only choose between certain answer options and cannot define independent questions.

- Free unbounded dialogue with the system

- This function has not been implemented. 


\begin{tabular}{|c|c|c|c|}
\hline Hardware & $\begin{array}{l}\text { Minimal system require- } \\
\text { ments }\end{array}$ & $\begin{array}{c}\text { Recommended system } \\
\text { requirements }\end{array}$ & $\begin{array}{l}\text { Used system require- } \\
\text { ments }\end{array}$ \\
\hline Processor & $\begin{array}{c}\text { Intel }^{\circledR} \text { Core }^{\mathrm{TM}} \text { i5-4590 } \\
3.3 \mathrm{GHz}(3.7 \mathrm{GHz})\end{array}$ & $\begin{array}{c}\text { Intel }^{\circledR} \text { Core }^{\mathrm{TM}} \text { i5-4590 } \\
3.3 \mathrm{GHz}(3.7 \mathrm{GHz})\end{array}$ & $\begin{array}{c}\text { Intel }^{\circledR} \text { Core }^{\text {TM }} \text { i7-6700K } \\
4.0 \mathrm{GHz}(4.2 \mathrm{GHz})\end{array}$ \\
\hline Graphic card & $\begin{array}{l}\text { NVIDIA GeForce }{ }^{T M} \\
\text { GTX } 970\end{array}$ & $\begin{array}{l}\text { NVIDIA GeForce }^{\text {TM }} \\
\text { GTX } 1070\end{array}$ & $\begin{array}{l}\text { NVIDIA GeForce } \\
\text { GTX } 1080\end{array}$ \\
\hline Memory & $4 \mathrm{~GB}$ & $4 \mathrm{~GB}$ & $16 \mathrm{~GB}$ \\
\hline $\begin{array}{c}\text { Operating sys- } \\
\text { tem }\end{array}$ & $\begin{array}{c}\text { Windows } 7 \text { SP1, } \\
\text { Windows } 81 \text { Windows } 10\end{array}$ & Windows 10 & Windows 10 \\
\hline
\end{tabular}

Tab. 1: Minimum, recommended and used system requirements for the HTV Vive Pro used (HTC Corporation 2020)

\subsection{Technical requirements}

The presentation of digital elements in virtual reality systems requires very low latencies to generate a smooth VR experience free from motion sickness and nausea. In order to create the ideal conditions for VR, a "motion-to-photon time" (time between sensor detection of the movement and the reaction on the screen) of less than 20 milliseconds (ms), corresponding to 50 FPS (frames per second), is aimed for (McCaffrey 2017). To investigate the performance of the computer for the VR application, three scenes were selected as examples based on the different complexity of the scenes (Figure 8). A computer located in the Photogrammetry \& Laser Scanning Lab of HafenCity University Hamburg was used for the subsequent investigation. As summarised in Tab. 1, the computer equipment used exceeds the recommended system requirements, which is a good qualification for optimal VR visualisation.
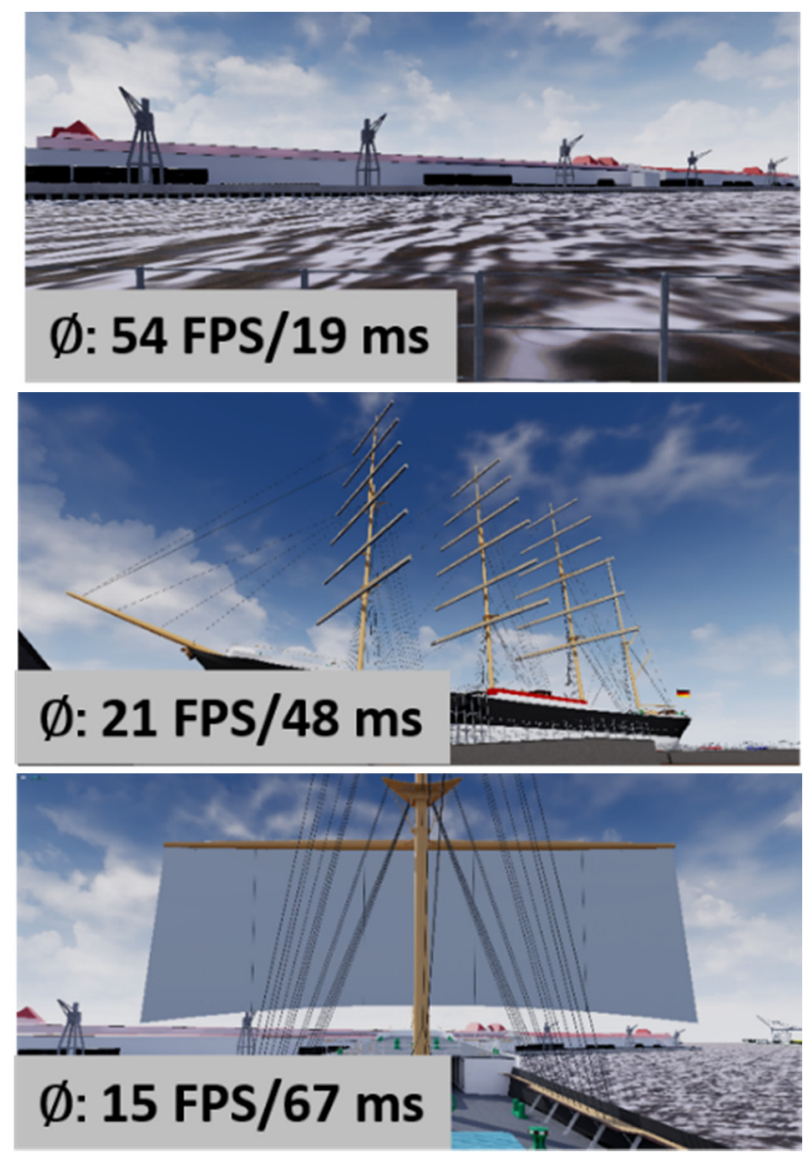

Figure 8. Performance of different scenarios: View over the harbour scene (top), view of the whole ship (centre) and physics simulation of a sail (bottom)
Rendering a view of the harbour with only a few environmental props and a low level of detail, peak values of up to $54 \mathrm{FPS} / 19$ ms (Figure 8 top) are achieved. As the number of models and textures increases, the performance correspondingly decreases, as is the case when the entire ship is in view $(\varnothing: 21 \mathrm{FPS} / 48 \mathrm{~ms}-$ Figure 8 centre). Due to the simulation of physics processes (such as the wind in the sails), the required computing power increases greatly and thus the visualisation is delayed, to the point that when looking at the sails ( $\varnothing: 15 \mathrm{FPS} / 67 \mathrm{~ms}$ - Figure 8 bottom) the user can clearly perceive the latencies at close range due to the dynamic process in the scenery.

\section{CONCLUSION \& OUTLOOK}

The objective of this project was to visualise the four-masted barque Peking in its state around the years 1927/1928 within a virtual reality application. At this point in time, the ship was still sailing on the Hamburg-Chile route as a sailing cargo ship. As an important part of Hamburg's history, this ship represents a unique subject for an immersive virtual experience (Figure 9 and Figure $10)$. In the course of this project, the formulated theoretical requirements of knowledge transfer through interactivity were examined and for the most part successfully implemented. It could thus be shown that Virtual Reality is capable of enabling a new form of knowledge transfer. There is potential for further optimization of this application with regards to allowing interactions with other people, a feature that was not implemented in this first version of the VR application. However, technologies do exist that allow cooperation and communication between several users at different locations in VR and have already been successfully tested in other projects at HafenCity University Hamburg (Kersten et al. 2018; Tschirschwitz et al. 2019). Regarding interactivity, it can be concluded that VR systems are only interactive to a certain degree and, importantly, that the handling of independently-formulated questions cannot yet be implemented comprehensively. The VR application and the interactive elements for knowledge transfer were tested by different users who are familiar with the ship. The feedback of these users was very positive but not documented by a questionnaire. However, a Hamburg journalist from the daily newspaper Hamburger Abendblatt describes the virtual visit to the Peking as a very realistic experience with options to broaden one's knowledge horizon (Ulrich 2020b).

The performance of the VR system is strongly dependent on the number of implemented elements, interactions and dynamic components. Maximum frame rates of 60 FPS are achieved, while in some sequences only an average of 15 frames per second is displayed. In particular, point cloud visualisations and the physics simulations of the ship's sails require large amounts of computing power. However, performance optimization was not a primary goal in this project. 
Furthermore, there are numerous opportunities for developing the project further, such as interactions, multiple users, serious games, and story-telling. Another option would be to allow for the visualisation to be viewed in a mobile-based AR application. In this variant, a protagonist in VR would control the action while onlookers would be able simultaneously to view the scenery though would not be able to intervene (e.g. according to Groove Jones 2017). In summary, the VR application described here is an example of how virtual reality can be used as a new means of knowledge transfer, using interactivity together with animation to enhance and facilitate the learning experience. It therefore has an increasingly important role to play in the future of educational media.

\section{ACKNOWLEDGEMENTS}

The authors would like to thank Ursula Richenberger, director of the Hafenmuseum, for the general support for the project. We acknowledge the information, technical drawings and 3D CAD model of the Peking which was provided by Helmut Radebold (TECHNOLOG services GmbH, Hamburg), the 3D model of the four-masted barque which was made available by Lars Spieckermann (Detlev Löll Ingenieurbüro GmbH, Peenemünde, Germany), the terrestrial laser scanning data of the Peking which was delivered by the engineering office Overath \& Sand Vermessungsbüro, Rendsburg, and for the assistance during the photogrammetric data acquisition of the auxiliary steering wheel by Dr. Ralf Wiechmann, Museum for Hamburg History.

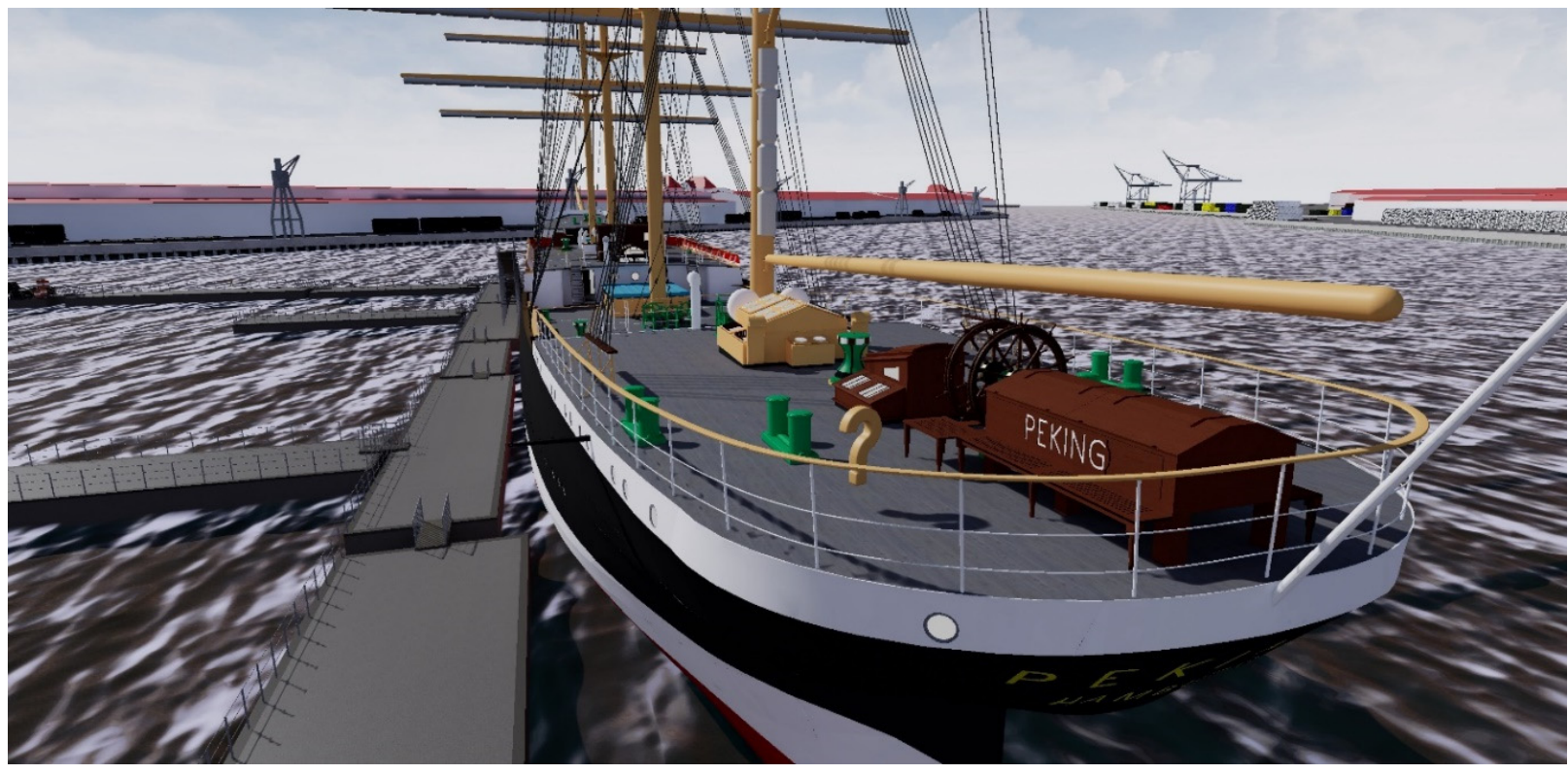

Figure 9. Overview of the deck of the four-masted barque Peking in the VR application

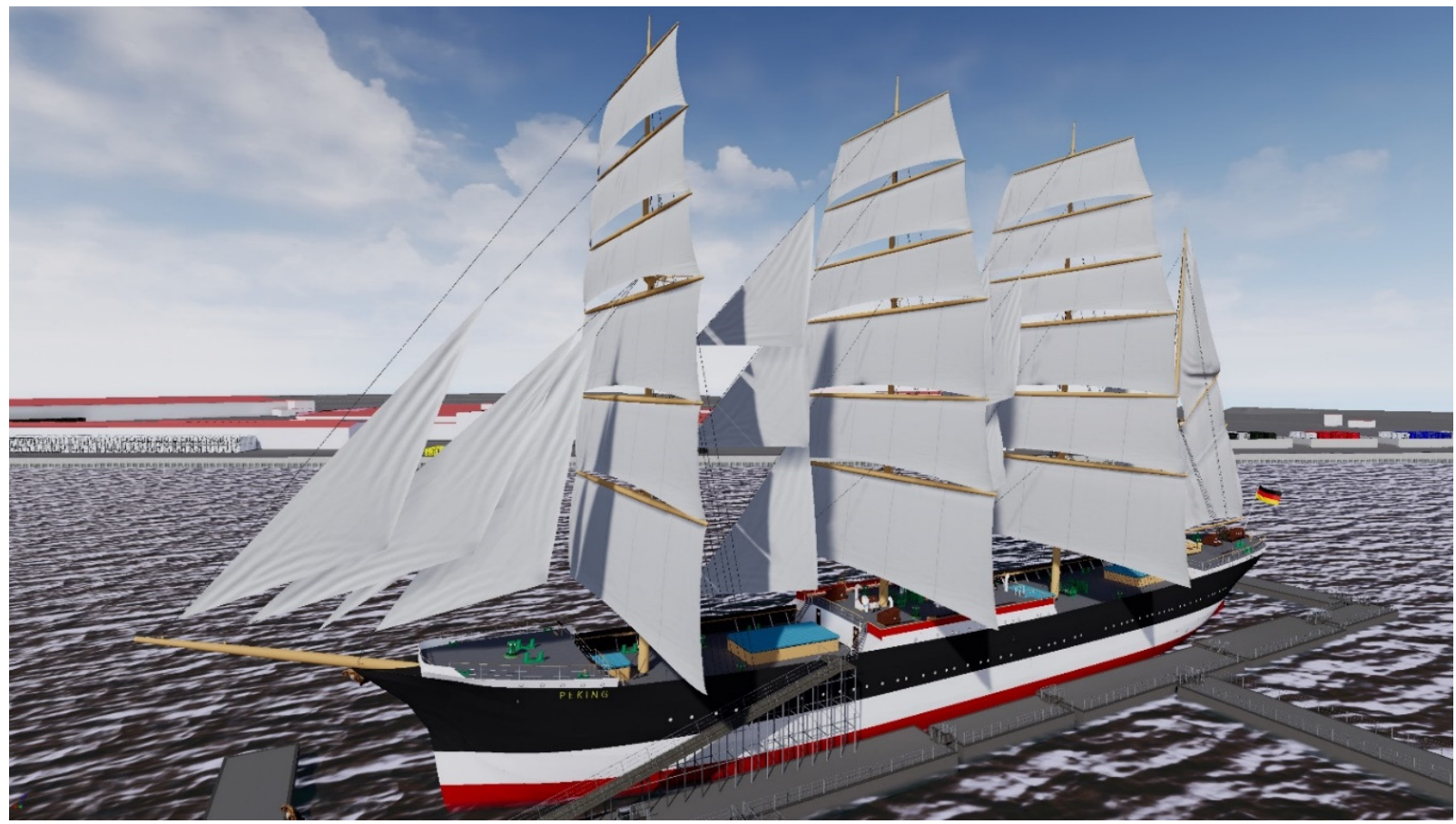

Figure 10. The Peking visualized in the VR application with sails set 


\section{REFERENCES}

Benkert, S., 2001: Wissensvermittlung mit neuen Medien Untersuchungen am Beispiel Niedrigenergie- und Solartechnik. Dissertation, Universität-Gesamtschule Siegen, http://webdoc.sub.gwdg.de/ebook/dissts/Siegen/Benkert2001.pd f.

Deggim, S., Kersten, T., Tschirschwitz, F., Hinrichsen, N., 2017: Segeberg 1600 - Reconstructing a Historic Town for Virtual Reality Visualisation as an Immersive Experience. Int. Arch. Photogramm. Remote Sens. Spatial Inf. Sci., XLII-2/W8, 87-94. doi.org/10.5194/isprs-archives-XLII-2-W8-87-20

Dörner, R., 2013: Virtual und Augmented Reality (AR/VR) Grundlagen und Methoden der Virtuellen und Augmentierten Realität. Springer-Verlag Berlin Heidelberg.

Epic Games, 2020: Unreal Engine 4 Documentation. https://docs.unrealengine.com/en-US/Resources/Showcases/ MatineeFightScene/index.html, last access 10.01.2020.

Freunde der Viermastbark Peking e.V., 2020: Four-Masted Barque PEKING. https://peking-freunde.de/en/index.php, last access 10.01.2020.

Groove Jones, 2017: AR + VR Mixed Reality: Look Into VR Worlds With an iPad. https://www.groovejones.com/mixed_reality_with_an_ipad_and _htc_vive/, last access 10.01.2020.

HTC Corporation, 2020: What are the system requirements https://www.vive.com/ca/support/vive-pro-

$\mathrm{hmd} /$ category_howto/what-are-the-system-requirements.html,

last access 10.01.2020.

Issing, L., Klisma, P., 2002: Information und Lernen mit Multimedia und Internet: Lehrbuch für Studium und Praxis. Beltz Weinheim.

Jakobsen, T., 2001: Advanced Character Physics. Game developers conference, (3), IO Interactive, Copenhagen, Denmark, 383-401.

Kersten, T., Hinrichsen, N., Lindstaedt, M., Weber, C., Schreyer, K., Tschirschwitz, F., 2014: Architectural Historical 4D Documentation of the Old-Segeberg Town House by Photogrammetry, Terrestrial Laser Scanning and Historical Analysis. Progress in Cultural Heritage. Documentation, Preservation, and Protection. 5th International Conference, EuroMed 2014, Limassol, Cyprus, November 3-8, 2014, Ioannides, M., Magnenat-Thalmann, N., Fink, E., Zarnic, R., Yen, A.-Y., Quak, E. (Eds.), Lecture Notes in Computer Science (LNCS), Vol. 8740, Springer International Publishing Switzerland 2014, 35-47.
Kersten, T., Lindstaedt, M., 2012a: Image-Based Low-Cost Systems for Automatic 3D Recording and Modelling of Archaeological Finds and Objects. Progress in Cultural Heritage Preservation, Lecture Notes in Computer Science (LNCS), Vol. 7616, Ioannides, M. et al. (eds.), Springer, Cham, 1-10.

Kersten, T., Lindstaedt, M., 2012b: Virtual Architectural 3D Model of the Imperial Cathedral (Kaiserdom) of Königslutter, Germany through Terrestrial Laser Scanning. EuroMed 2012 Int. Conference on Cultural Heritage, Ioannides, M.; Fritsch, D.; Leissner, J.; Davies, R.; Remondino, F.; Caffo, R. (Eds.), Lecture Notes in Computer Science (LNCS), Volume 7616, SpringerVerlag Berlin Heidelberg, 201-210.

Kersten, T., Tschirschwitz, F., Deggim, S., Lindstaedt, M., 2018: Virtual Reality for Cultural Heritage Monuments - from 3D Data Recording to Immersive Visualisation. Digital Heritage Progress in Cultural Heritage: Documentation, Preservation, and Protection, Part II, Lecture Notes in Computer Science (LNCS), Vol. 11197, Ioannides, M. et al. (eds.), Springer, Cham, 74-83.

McCaffrey, M., 2017: Unreal Engine VR Cookbook: Developing Virtual Reality with UE4. Addison-Wesley Professional, 1st edition, $288 \mathrm{p}$.

Tschirschwitz, F., Richerzhagen, C., Przybilla, H.-J., Kersten, T., 2019: Duisburg 1566: Transferring a Historic 3D City Model from Google Earth into a Virtual Reality Application. PFG Journal of Photogrammetry, Remote Sensing and Geoinformation Science, 87(1-2), 47-56.

Ulrich, F., 2020a: Die "Peking" wird wieder zur Grande Dame. Hamburger Abendblatt, 4 January 2020, https://www.abendblatt.de/hamburg/article228054579/pekingrestaurierung-schiff-frachtsegler-hafen.html, last access 12.01.2020.

Ulrich, F., 2020b: Mit Virtual-Reality-Brille an Bord der "Peking" gehen. Hamburger Abendblatt, 14 March 2020, https://www.abendblatt.de/hamburg/article228694871/hamburghcu-forscher-virtuell-rundgang-peking.html, last access 15.03.2020.

Walmsley, A. P., Kersten, T., 2019: Low-cost Development of an Interactive, Immersive Virtual Reality Experience of the Historic City Model Stade 1620. Int. Arch. Photogramm. Remote Sens. Spatial Inf. Sci., XLII-2/W17, 405-411. doi.org/10.5194/isprs-archives-XLII-2-W17-405-20. 